\title{
Tese, Síntese, Antítese: Contributos para uma Teoria Dialéctica das Organizações
}

\author{
Miguel Pina e Cunha \\ João Vieira da Cunha
}

\section{RESUMO}

Gerir organizações parece ser uma tarefa cuja complexidade e dificuldade vai crescendo ao longo do tempo. Neste texto destacamos um dos principais motores dessa complexidade que parece merecer maior destaque do que aquele que lhe tem sido dado: a presença simultânea de duas abordagens antagónicas, que exercem forte pressão normativa sobre quem pratica a gestão. Recorrendo a um modelo dialéctico de construção de teoria, é proposto um modelo de organização e estratégia que resulta da síntese/confronto destas duas abordagens e que aparenta ser, ao mesmo tempo, suficientemente próximo da realidade para ser rotulado como descritivo e suficientemente distante para possuir algum poder normativo.

Palavras-chaves: síntese; dialéctica; teoria organizacional.

\begin{abstract}
Business management seems to be a task whose complexity and difficulty just keeps growing. In this article, we present one of the major engines of this complexity - one that seems worthy of more attention than it has received until now - the simultaneous presence of two antagonic approaches to management that exert a strong normative pull over this activity. Using a dialectic model of theory building, an organization/strategy model resulting from the synthesis/confrontation between these approaches is proposed. This model appears to be both sufficiently close to managerial practice to be labeled as descriptive, and sufficiently distant to still hold some normative power.
\end{abstract}

Key words: synthesis; dialectic; organization theory. 


\section{INTRODUÇÃO}

Quem pratica e estuda gestão sente-se muitas vezes no meio de um combate entre as forças do bem e as forças do mal (Perrow, 1973). Por um lado, a esmagadora maioria dos textos populares sobre gestão exalta as histórias de sucesso de autênticos heróis de gestão aclamados pela imprensa de negócios, cuja proficiência e competência num conjunto de práticas aparentemente estranhas - que vão contra todas as normas do racionalismo económico e impessoal - geram lucro e mais lucro (e.g. Peters, 1992; Branson, 1998). Estes autores apelam, muitas vezes de forma explícita (e.g. Senge, 1990), a uma autêntica cruzada a favor de um qualquer capitalismo humanista que supostamente deve substituir o capitalismo economicista de forma a permitir uma progressão de facto da humanidade. Do lado das forças do mal está a abordagem tradicional, que nasceu no princípio do século com o trabalho de Taylor (1947), e que defende que, com base no pressuposto de que o homem é um ser essencialmente racional, a tarefa da gestão consiste essencialmente em planear, organizar, decidir e controlar a actividade da organização de acordo com métodos quase-científicos (Barnard, 1938) e, segundo os seus opositores, alienadores e desumanizantes (e.g. Peters, 1987), de forma a assegurar níveis óptimos de eficiência produtiva - um modelo que, apesar de impopular, parece ainda dominar o folklore que povoa a mente da maioria das pessoas que exerce gestão (Mintzberg, 1975). Apesar de se posicionarem em pólos opostos, nenhuma destas correntes se encontra, no entanto, significativamente relacionada com a experiência da prática da gestão (Sayles,1989), podendo levar aqueles que a exercem, devido às inúmeras pressões que sobre eles recaem, a sucumbir a um situação em que, na tentativa de agradar a todos os stakeholders, de vestir a forma organizacional da moda, e de lidar com um número crescente de problemas e oportunidades, a organização pode cair assim numa situação que ameace os seus resultados e, em última análise, a sua sobrevivência. Nenhuma destas alternativas parece factível porque (1) ambas as teorias puxam muito pela realidade (impossibilitando a aproximação da prática a qualquer um dos modelos normativos) e (2) porque, por um lado, (a) a indústria dos gurus tem que a puxar para continuar vendável (Micklethwait e Wooldridge, 1996) e porque, por outro, (b) o modelo tradicional ainda está demasiadamente entrincheirado naquilo que tem sido socialmente construído como o papel do gestor - este fenómeno tem vindo a gerar uma tensão que exige ser resolvida (Fritz, 1989). 


\section{Organizaçóes: uma Perspectiva Dialéctica}

No entanto, é interessante observar que se transportarmos o confronto entre ambas as correntes de uma forma teleológica para uma forma dialéctica (Van de Ven e Poole, 1995), é possível encontrar um modelo muito mais próximo daquilo que tem vindo a ser descrito como a realidade da gestão, mas que mantém algum poder normativo. Utilizar um modelo dialéctico significa procurar um novo estado, neste caso uma nova corrente através do confronto entre os dois pólos de um paradoxo (Poole e Van de Ven, 1989). Em vez de escolher entre centralização e descentralização, chegar a um meio termo entre eficácia e eficiência e procurar um compromisso entre autonomia e controlo, o que argumentamos é que é possível que cada uma destas dialécticas exista em simultâneo na organização - aumentando também a capacidade desta em prosperar em envolventes de alta velocidade. Alguns autores, mesmo até no campo normativo, já fizeram um esforço neste sentido (e.g. Peters, 1987). No entanto, a simultaneidade de duas forças contraditórias é meramente um artifício semântico. De facto, quando interrogado sobre qual seria a lição que gostava de legar à Humanidade, Peters (1995, p. 41) refere o seguinte paradoxo: "o sucesso resulta de relações estreitas, mas as relações estreitas destroem a capacidade de adaptação [garantia de insucesso, mesmo a curto prazo, nas envolventes turbulentas de hoje (Peters, 1992)]". Por outras palavras, Peters (1995) afirma que o sucesso resulta do aumento da eficiência, mas que esse aumento leva a uma redução na capacidade de procurar a eficácia o que, num ambiente de mudança, conduz rapidamente ao insucesso. Contudo, se abordarmos este paradoxo de uma forma dialéctica, a síntese resultante da justaposição de tese (eficácia) e antítese (eficiência) ${ }^{(1)}$ resulta naquele que é sentido como um dos principais desafios da gestão de hoje - ser tão competente na exploração por investigação (detectar problemas e descobrir oportunidades) como na exploração por utilização (resolver problemas e aproveitar oportunidades).

Este desafio abarca assim dois tipos de problemas: (1) problemas de eficácia, que se reportam a questões ligadas à estratégia (qual é a coisa certa a fazer?) e (2) problemas de eficiência, que têm a ver com questões ligadas à organização (como fazer as coisas bem?). Consequentemente, ao alargar este exercício de dialéctica a um conjunto mais amplo de áreas da gestão e das organizações, fá-loemos classificado-as como relacionadas com a estratégia ou com a organização, tendo em conta que estas duas áreas - que além de serem as mais críticas para quem exerce a gestão no seu quotidiano - aparecem muitas vezes emparelhadas, quando se fala de teoria das organizações (Weick, 1979; Mintzberg, 1995; Quinn, 1995). O nosso objectivo é, assim, tendo esta categorização como referência, fazer emergir um modelo que, apesar de resultar do confronto entre a teoria dita 
tradicional e a moderna, esteja mais próximo dos desafios centrais da gestão de organizações nos nossos dias, do que as duas correntes que lhe servem de input.

\section{Estratégia}

\section{Tese (A1): Nas organizações do futuro, os trabalhadores planeiam e os traba- lhadores executam.}

Todas as teorias que se incluem na corrente dita moderna, apelam a um elevado grau de participação dos trabalhadores no processo de planeamento. Tomando como ponto de partida a definição de planeamento estratégico de Harrison (1987) (estratégia como resposta às perguntas: o que vender, como produzir/vender e onde vender), podemos ver que este argumento assenta em duas proposições: em primeiro lugar, (1) apenas as pessoas mais próximas da acção/mercado possuem a informação necessária para responder às perguntas o que vender? e onde vender?; em segundo lugar (2) apenas as pessoas mais familiarizadas com a tecnologia e com o produto é que possuem a informação adequada para responder à pergunta como produzir/vender? Estas proposições são resultantes de quatro condicionantes. Em primeiro lugar (1) ter uma elevada dose de responsabilidade no processo de planeamento confere ao trabalhador uma percepção de autonomia que tem efeitos motivadores não negligenciáveis (Hackman e Oldham, 1976). Depois, (2) o conhecimento explícito ou articulável que os trabalhadores possuem deve ser utilizado por eles próprios como input para o planeamento já que fazê-lo chegar aos níveis organizacionais a quem é normalmente atribuído o papel de decisor levaria muito tempo - um problema em envolventes de alta velocidade (Stalk, 1988). Além disso, (3) os enviesamentos típicos da comunicação vertical nas organizações (Handy, 1976) distorceriam a informação antes desta chegar ao topo. Por último, (4) existe uma parte importante do conhecimento utilizado pelos trabalhadores no processo de planeamento que é implícita (Nonaka, 1991) e por isso não articulável nem transmissível. Por tudo isto, esta abordagem defende que devem ser os trabalhadores a planear a sua própria acção, e a executá-la posteriormente (Byham e Cox, 1998).

\section{Antítese (A1): Nas organizações de sucesso, os gestores planeiam e os traba- lhadores executam.}

O princípio da separação entre planeamento e execução foi um dos grandes avanços científicos na gestão do início do século. De acordo com Taylor (1947), o fundador desta corrente, apenas as pessoas com capacidade e conhecimento 
para aplicar o método científico ao trabalho (neste caso, operário) são suficientemente competentes e distantes do processo produtivo para não serem contaminadas pelo conhecimento tácito (e, na perspectiva de este autor, imperfeito) que aí abunda. Só através da gestão científica do trabalho é possível conceber o melhor processo produtivo para a organização em causa (responder a pergunta como produzir/vender?). A segunda onda racionalista na área da gestão veio enriquecer esta corrente com instrumentos de análise da envolvente externa, tornando-a adequadamente equipada para viver num mundo sistémico, aberto e em mudança (Robbins, 1990). Deste modo, aquilo que podemos chamar a avaliação científica da envolvente, passou a permitir a esta corrente responder as perguntas onde vender? e o que vender?, através dos modelos de portfolio e da industrial organization (Pettigrew e Whipp, 1993; Andrews, 1995; Porter, 1998). A motivação dos trabalhadores, assente no paradigma do homo economicus, era aqui assegurada pelo incremento dos salários (Taylor, 1947). Em envolventes em rápida mudança e de grande complexidade (crise), o melhor tipo de liderança é a centralizada/autoritária, que afirmam ser rápida e eficaz (Bass e Stogdill, 1990), baseando-se no pressuposto de que um nível de capacidade elevado ultrapassa a compreensão dos trabalhadores, competindo por isso à gestão entendê-lo e levar a cabo o planeamento estratégico que depois será desdobrado em tarefas simples, executáveis pelos trabalhadores.

\section{Síntese (A1): Nas organizações os gestores e trabalhadores planeiam e execu- tam em simultâneo.}

Da justaposição de tese e antítese, podemos retirar que a turbulência sentida na envolvente e a complexidade organizacional tornam as tarefas de gestores e trabalhadores pouco susceptíveis de planeamento prévio por parte de uns ou de outros (Moorman e Miner, 1998). Neste caso, quer a gestão quer os trabalhadores planeiam em tempo real, mas fazem-no em relação a eixos de acção distintos. Os gestores estão mais preocupados com inovações a nível organizacional e macroambiental (grandes tendências - envolvente contextual), enquanto os trabalhadores se preocupam com inovações a nível de mercado/produto e a nível microambiental (pequenas tendências - envolvente de transaccional) (Crossan e Sorrenti, 1997). A motivação aqui é potencialmente maior do que em qualquer um dos casos anteriores, já que para além da autonomia decorrente da liberdade de planeamento, um novo elemento do modelo de Hackman e Oldham (1976) é activado: o feedback. A convergência do planeamento e da execução dá a quem a pratica um feedback imediato das suas acções e decisões (Gardner e Rogoff, 1990). À crescente velocidade e complexidade da envolvente, a organização responde com planeamento em tempo real, quer ao nível estratégico quer ao nível operacional, maximizando a sua capacidade de adaptação. 


\section{Tese (A2): Nas organizações do futuro é privilegiada a eficácia - os gestores devem 'fazer as coisas certas'.}

Esta abordagem afirma que a envolvente é uma fonte constante de turbulência e de mudança. Para sobreviver, a organização está sujeita ao efeito da rainha de copas (Kauffman, 1995): para ficar no mesmo sítio (posição competitiva) tem de estar sempre a correr (inovar/mudar). A competência nuclear das organizações neste tipo de envolventes é a de explorar por investigação, ou seja a de procurar ou criar novas tecnologias, mercados ou produtos (Hamel e Prahalad, 1994). A eficácia é o seu valor guia, já que a eficiência pode, neste tipo de envolventes, resultar rapidamente numa situação em que a empresa se está a esforçar por produzir e vender cada vez melhor um produto que já ninguém quer. Recorrendo à definição de Drucker (1993), o papel de quem dirige organizações neste tipo de envolventes é o de líder - é aquele que impele à mudança, aquele que se preocupa com fazer as coisas certas (do the right thing). Adoptando um modelo teleológico de mudança (Van de Ven e Pooole, 1995), a sua função reparte-se pelas seguintes responsabilidades: (1) conceber um estado futuro; (2) veicular uma percepção do estado actual; e (3) incentivar a mudança. Conceber um estado futuro assenta essencialmente em construir uma visão adequada, por um lado, ao estado futuro esperado da envolvente e, por outro, às necessidades e aspirações partilhadas pelos membros da organização (Collins e Porras, 1997). Veicular uma percepção do estado actual implica, essencialmente, transmitir um sentimento de desconforto com o presente e de urgência de mudar (Van de Ven e Poole, 1995), pondo o acento tónico na distância entre este e o estado futuro desejado. Incentivar a mudança assenta essencialmente em criar histórias e mitos organizacionais que valorem positivamente comportamentos pró-mudança, permeabilizando a organização para este processo, via cultura (Senge, 1990). De notar, no entanto, que alguns autores (e.g. Fritz, 1989) defendem que a mera existência de uma percepção de um estado actual diferente de um estado futuro desejado é suficiente para despoletar a mudança, carecendo assim este processo de qualquer incentivo. Em suma, esta corrente defende que a função central de quem dirige a organização se reporta à gestão dos seus negócios futuros - ou seja, maximizar a capacidade de gerar lucros (profitability). A organização sobrevive, gerando estrelas, mas sempre à custa de sacrifícios de rentabilidade que, em última análise, a podem esvaziar de recursos pondo em causa a sua longevidade.

\section{Antítese (A2): Nas organizações de sucesso é privilegiada a eficiência - os gestores devem 'fazer as coisas bem'.}

Esta abordagem afirma que a envolvente se caracteriza por períodos de estabilidade interrompidos por surtos infrequentes de turbulência e de mudança. A com- 
petência nuclear das organizações neste tipo de envolventes é a de explorar por utilização, ou seja a de rentabilizar as suas tecnologias, mercados ou produtos correntes, até a próxima descontinuidade, altura em que deve procurar adaptar-se o melhor possível (Romanelli e Tushman, 1994). A eficiência é o seu valor guia, já que procurar a eficácia em envolventes de grande concorrência pode resultar rapidamente numa situação em que a empresa se está a esforçar por produzir e vender produtos cada vez melhores que ninguém tem dinheiro para comprar. Voltando à definição de Drucker (1993), o papel de quem dirige organizações neste tipo de envolventes é o de gestor - é aquele que impele à maximização dos resultados em simultâneo com a minimização dos inputs, aquele que se preocupa com fazer as coisas bem (do things right). Esta função reparte-se nas seguintes tarefas: (1) planeamento; (2) implementação; e (3) controlo (Fayol, 1949). No planeamento, o gestor traça os objectivos da organização e os processos mediante os quais esses objectivos vão ser alcançados. Na implementação, põe esses sistemas em funcionamento. No controlo verifica se o processo corre conforme planeado e introduz as correcções necessárias para garantir que os objectivos iniciais são atingidos. Sinteticamente, esta abordagem afirma que a função central de quem dirige a organização se reporta à gestão dos seus negócios actuais - ou seja, maximizar os lucros (profit). A organização prospera gerando vacas leiteiras, mas sempre à custa de sacrifícios de flexibilidade que, em última análise, a podem esvaziar de mercado (e, consequentemente, de recursos) pondo em causa a sua longevidade.

\section{Síntese (A2): Nas organizações é privilegiada a eficácia eficiente - os gestores devem 'fazer bem as coisas certas'.}

Aqui defendemos que a envolvente se caracteriza por períodos de mudança incremental contínua, que vai gerando surtos infrequentes de turbulência e de mudanças radicais. A competência nuclear das organizações neste tipo de envolventes é a de explorar por utilização a exploração por investigação, ou seja, a de rentabilizar as novas tecnologias, mercados ou produtos que descobriu ou criou (Brown e Eisenhardt, 1997). A eficácia eficiente é o seu valor guia. Ainda com base em Drucker (1993), o papel de quem dirige organizações neste tipo de envolventes é o de líder gestor - aquele que impele à descoberta de novas oportunidades que possam ser transformadas em motores (geradores) de lucro, aquele que se preocupa com fazer bem as coisas certas (do the right thing right). Esta função reparte-se nas seguintes tarefas: (1) catalisar a construção de uma visão orientadora; e criar uma cultura de (2) mudança e de (3) obtenção de resultados. Catalisar a construção de uma visão orientadora significa participar na actividade de construção de significado (sensemaking) da organização, de forma que a interpretação imposta sobre o padrão de acções desta tenha uma valoração positiva par- 
tilhada pelos seus membros, capaz de servir como mecanismo de coordenação da sua acção futura e de input para futuras construções de significado, reforçando o seu papel (Weick, 1979). Criar uma cultura de mudança é importante para fomentar a actividade de exploração por investigação e reporta-se, como já foi dito acima, a criar histórias e mitos organizacionais que valorem positivamente comportamentos pró-mudança, permeabilizando a organização para este processo, via cultura (Senge, 1990). Criar uma cultura de obtenção de resultados tem como objectivo fomentar a actividade de exploração por utilização, de modo que as oportunidades descortinadas no processo centrado na eficácia, possam ser rentabilizadas para realimentar esse processo. Em resumo, esta abordagem afirma que a função central de quem dirige a organização se reporta à gestão dos seus negócios actuais de forma a gerarem negócios futuros - ou seja, maximizar a lucratividade dos lucros (profitable profitability). A organização sobrevive e prospera gerando vacas leiteiras estrelas, explorando por utilização as oportunidades que vai descortinando via exploração por investigação, o que, em última análise, lhe vai repondo recursos e promovendo a longevidade.

\section{Tese (A3): Nas organizações do futuro, a mudança é incremental.}

Como pode ser detectado ao longo do que até aqui foi escrito, a cada uma das correntes está subjacente um pressuposto em relação à natureza da inovação/ mudança. As abordagens que aqui designamos por modernas afirmam que o sucesso, e até a própria sobrevivência da organização só são possíveis se esta inovar continuamente (Imai, 1989; Peters, 1992). Isto deve-se, essencialmente, à redução dos ciclos de vida: (1) dos produtos, gerada quer (a) pela concorrência acrescida que se tem vindo a sentir em muitos sectores, quer (b) por alterações qualitativas cada vez mais frequentes nos padrões de procura (D'Aveni, 1995); (2) das tecnologias de produção, que resulta essencialmente da concorrência que se faz sentir nesses sectores (Bettis e Hitt, 1995); e (3) das práticas de gestão/administrativas, essencialmente induzida pela indústria da consultoria (Abrahamson, 1991). Isto implica que essa inovação não deve ficar só pela oferta ao cliente, mas deve também abarcar todo o processo de produção e entrega dessa oferta, incluindo a organização que lhe está subjacente. Estas inovações podem ser de índole incremental ou radical, mas devem sempre resultar num fluxo contínuo de mudança. Normalmente estes dois tipos aparecem como exclusivos, ou seja, para alguns autores só tem sentido a mudança radical (Hamel e Prahalad, 1994), enquanto para outros só o tem a incremental (Imai, 1989). Do nosso ponto de vista, e apesar do optimismo de alguns autores (DeBono, 1986), a pressão para a produção de inovações/mudanças a uma cadência acelerada ultrapassa a capacidade humana, quer ao nível do indivíduo quer do grupo, de desaprender de maneira fundamental, os modelos mentais que estes detêm em relação à indústria onde trabalham (Argyris, 1985) - a mudança contínua tende a ser, por isso, incremental. 


\section{Antítese (A3): Nas organizações de sucesso, a mudança é pontuada.}

Partindo da mesma percepção do panorama competitivo mencionado acima, a corrente de pensamento que aqui designamos de tradicional tem uma perspectiva oposta à anterior (e.g. Porter, 1998). Esta abordagem afirma que a única mudança relevante na envolvente é a mudança radical, já que é esta que detém o poder de deixar a organização órfã de mercado (Hamel e Prahalad, 1994). Além disso, defende que este tipo de mudança ocorre infreqüentemente e é mediado por períodos mais ou menos longos de estabilidade. Tendo isto em conta, a organização, além de tomar partido destes períodos de estabilidade, deve, perante mudanças radicais na envolvente, operar também em si uma mudança deste tipo, para sobreviver, retornando depois a um período de estabilidade (Van de Ven e Poole, 1995).

As inovações/mudanças nas empresas ocorrem, assim, de forma pontuada e são de natureza radical.

\section{Síntese (A3): Nas organizações a mudança é incrementalmente pontuada.}

Mantendo a percepção de hipercompetitividade na envolvente (D'Aveni, 1995), podemos dividir as mudanças que esta provoca em dois tipos, uma (1) incremental/contínua, de índole essencialmente quantitativa cuja sedimentação, ao longo do tempo, faz emergir mudança (2) pontuada/radical, de índole qualitativa.

O desafio que se coloca às organizações é, em consequência, o de importar este processo, levando a cabo mudanças incrementais de forma contínua, de modo a fazer emergir no seu interior, agora de forma pontuada, mudanças radicais (Eisenhardt e Tabrizi, 1995; Brown e Eisenhardt, 1997).

\section{Tese (A4): Nas organizações do futuro, a primazia é dada à excelência nas competências e nos conhecimentos.}

Baseando-se de novo na turbulência sentida na maioria das envolventes actuais (Emery e Trist, 1965) e na necessidade de eficácia organizacional que esta acarreta, esta abordagem defende a primazia do conhecimento/competências em relação à tecnologia/inputs. A argumentação subjacente a esta proposição diz que a eficácia resulta de uma idéia clara e economicamente factível de um estado futuro desejado e do desenvolvimento de um processo que o permita atingir. A concepção do estado futuro requer uma percepção clara/partilhada da envolvente, e das tendências que nela vão emergindo, assentando por isso na capacidade de evitar enviesamentos de percepção oriundos de rotinas defensivas (Argyris, 1985) e na capacidade de aprender em grupo (Senge, 1990; Bohm, 1996). A concepção do processo para atingir a visão desejada é, na sua essência, um exercício de criativi- 
dade. A proficiência da organização no desempenho desta competência depende basicamente da diversidade que detém no seu interior, e da sua capacidade de a potenciar via interacção dos seus membros (Baker, 1994; Amabile, 1998). Donde resulta que, para que a organização seja eficaz, é mais importante a diversidade do seu stock de conhecimento e as competências de criatividade e aprendizagem dos seus membros, do que a abundância de inputs ou a presença de uma tecnologia muito sofisticada. Em última análise, as competências e o conhecimento são privilegiados porque são mais flexíveis e estão mais orientados para a exploração por investigação, enquanto inputs e tecnologia possuem um maior grau de inércia e estão mais orientados para a exploração por utilização.

\section{Antítese (A4): Nas organizações de sucesso, a primazia é dada à excelência na tecnologia e nos inputs.}

Esta corrente, ao contrário da anterior, retira da turbulência sentida na maioria das envolventes actuais a necessidade de maior eficiência - $\mathrm{o}$ aumento da concorrência implica ou a produção de produtos mais baratos ou a de produtos de melhor qualidade (física) (Porter, 1998). Este aumento de eficiência pode resultar essencialmente de dois factores: (1) de uma maior eficiência na obtenção de inputs (mais baratos ou de melhor qualidade) conseguida através de alianças com fornecedores, metodologia just-in-time etc (Peters, 1987); ou de uma maior eficiência no processo (custos mais baixos, melhor qualidade física), que assenta fundamentalmente na tecnologia utilizada (em sentido amplo, ou seja, hardware - máquinas - e software - organização do trabalho) (Deming, 1986; Juran, 1988; Imai, 1989). Disto resulta que, para que a organização seja eficiente, são mais importantes os inputs e a tecnologia utilizada, já que são mais especializados e orientados para a exploração por utilização, do que a diversidade do seu stock de conhecimento e as competências de criatividade e aprendizagem dos seus membros, que são mais horizontais e estão mais orientadas para a exploração por investigação.

\section{Síntese (A4): Nas organizações, a primazia é dada à excelência no bricolage (excelência no conhecimento para ter excelência na tecnologia).}

Da necessidade de reagir em tempo real a alterações na envolvente, e de procurar a eficácia eficiente, advém a necessidade de resolver problemas e aproveitar oportunidades sem que estejam disponíveis os recursos óptimos para o efeito (Weick, 1993). Para que isto seja possível, é necessário que a empresa possua (1) um conjunto mínimo de recursos horizontais críticos (Weick, 19--); (2) a competência e o conhecimento suficiente desses factores para os alocar às tarefas necessárias à exploração por utilização de oportunidades/problemas detectados na envolvente (Eisenberg, 1990); (3) uma percepção compatível do estado futuro dese- 
jado (Bastien e Hostager, 1988). Em suma, deste ponto de vista, a competência e o conhecimento são capazes de horizontalizar/generalizar um conjunto limitado de recursos, de modo que sejam suficientemente flexíveis para serem adaptáveis a qualquer oportunidade/problema (permitir a exploração por utilização), servindo esses recursos como uma fonte de coordenação entre os membros de uma organização, de forma semelhante ao papel desempenhado pela pauta de uma canção para um grupo de improvisadores de $j a z z$, por oposição ao papel que esta desempenha para uma orquestra (Weick, 1990).

\section{Tese (A5): Nas organizações do futuro ouve-se ao máximo o máximo de pes- soas possíveis.}

Esta proposição assenta em dois argumentos. Por um lado, o aumento da complexidade externa (contextual e transaccional), em especial no que se reporta às alterações dos padrões de consumo, implica que a empresa desenvolva esforços deliberados por ter uma comunicação estreita com o seu mercado, de forma que as suas inovações sejam bem sucedidas (Kotler, 1992). Por outro lado, o aumento da complexidade interna leva a que (1) apareçam problemas não antecipáveis no interior das organizações (Stacey, 1996) e que (2) esses problemas não sejam resolúveis pela vontade ou acção de um indivíduo isoladamente. Isto implica que a gestão da organização deve manter canais de comunicação directos com várias partes da organização, de modo (1) a detectar potenciais problemas/oportunidades (Peters e Waterman, 1982) e (2) facilitar a implementação e adopção de soluções/inovações para enfrentar esses problemas/oportunidades. Em síntese, o topo da organização deve procurar ouvir continuamente os restantes membros, e a empresa como um todo deve ter a mesma preocupação em relação ao mercado que serve.

\section{Antítese (A5): Nas organizações de sucesso não se ouve ninguém.}

A corrente tradicional adopta uma posição simétrica à anterior. Em relação à complexidade externa, e tendo em conta que, para esta corrente, a inovação/mudança ocorre de forma pontuada e é de natureza radical, é defendido que compete às organizações antecipar a procura e criar necessidades (Hamel e Prahalad, 1994). Ouvir os destinatários da inovação é uma etapa que ocorre já muito no fim do seu processo de desenvolvimento (Cooper, 1994). No que diz respeito à complexidade interna, esta corrente partilha de uma visão contingencial da organização (Lawrence e Lorsch, 1967). Todas as formas organizacionais têm vantagens e inconvenientes - compete à gestão, depois de analisada a envolvente, decidir qual a melhor forma e a partir daí viver com tudo o que esta tem de positivo, e com tudo o que tem de negativo. Em suma, a organização pode (e deve) ter um comportamento 
quase autista, quer no que diz respeito ao que se passa no seu interior, quer no que se refere ao mercado que serve.

\section{Síntese (A5): Nas organizações ouve-se algumas pessoas, algumas vezes.}

Do confronto das duas posições anteriores, emerge uma abordagem que permite entender o sucesso de algumas inovações, que as restantes deixam sem explicação, como é o caso da introdução do rato na interface entre computador e utilizador (Levy, 1995). Ao nível da complexidade externa, ouvir algumas pessoas, algumas vezes, implica escutar activamente clientes (actuais/futuros) relevantes, procurando as suas necessidades subjacentes, muitas vezes não articuláveis; depois a organização deve assumir uma posição autista de forma a estar livre para encontrar soluções criativas para atender essas necessidades, testadas através da experimentação (Weick, 1990; Peters, 1992). Em relação à complexidade interna, esta postura implica procurar também o que está subjacente aos problemas/oportunidades levantados pelos trabalhadores, e servir de catalisador no processo de criação de significado (sensemaking) de forma a enquadrar esses desafios de modo a permitir que sejam os próprios membros a planear a melhor maneira de os enfrentar, à medida que a acção se desenrola. Trata-se então de praticar um autismo aberto, quer nas relações intra-organizacionais, quer nas relações empresa-mercado.

\section{OrganizaÇĀo}

\section{Tese (B1) : Nas organizações do futuro, o trabalho é em equipa.}

Uma das decisões que a maioria dos manuais apresenta como fazendo parte da gestão de topo reporta-se à alocação de determinadas tarefas à equipa ou ao indivíduo.

As correntes mais recentes de gestão, em especial as de índole normativa, têm apregoado as vantagens do trabalho em equipa, argumentando que a complexidade da envolvente deve ser complementada com complexidade organizacional. Consequentemente, as tarefas que incluem pontos de interacção com a envolvente devem ser desempenhadas por equipas multifuncionais que, por hipoteticamente possuírem um maior grau de diversidade, são capazes de ter uma percepção mais clara dos sinais enviados pela envolvente e de gerar soluções mais adequadas aos desafios colocados por esta (Katzenbach e Smith, 1994). Peters (1987, p. 302) chega mesmo a afirmar (e literalmente sublinhar) que "a força do conceito de equipa é tal, que na maior parte das vezes é aconselhável violar o aparente senso 
comum e forçar uma estrutura de equipa em quase todas as actividades". Para esta corrente teórica, é a equipa, e não o indivíduo, que constitui o elemento nuclear de uma organização.

\section{Antítese (B1): Nas organizações de sucesso, o trabalho é individual.}

A teoria tradicional centra-se no indivíduo (e.g. Taylor, 1947; Fayol, 1949), preocupando-se apenas com grupos e equipas na medida em que estes afectam a racionalidade e desempenho deste. Assim, para esta corrente, os grupos possuem desvantagens que os tornam perigosos para enfrentar um ambiente em mudança. A sua criatividade é menor do que a do indivíduo, e estão impregnados de fenómenos que reduzem a sua racionalidade e conhecimento, na melhor das hipóteses, ao nível do pior dos seus elementos. O pensamento grupal (groupthink) que leva à tomada de decisões que do ponto de vista de um observador externo são completamente desprovidas de racionalidade (Janis, 1971) e o paradoxo de Abilene, segundo o qual um grupo é capaz de empreender um curso de acção que não é desejado por nenhum dos seus membros individualmente (Harvey, 1996), constituem exemplos deste argumento.

\section{Síntese (B1): Nas organizações, o trabalho é individual em equipa.}

Das duas abordagens anteriores resulta o conceito do individualismo em equipa. A equipa aparece de facto como o elemento nuclear da organização, essencialmente porque aglutina a diversidade necessária para uma maior eficácia a nível de tomada de decisão e criatividade (Brown e Eisenhardt, 1997). No entanto, as relações entre os membros da equipa são diferentes da intimidade preconizada pela tese anterior. Aqui, a relação membro-grupo é de intersecção e não de inclusão (Barrett, 1998), ou seja, o indivíduo contribui para o grupo mas não se lhe entrega, mantendo assim a distância necessária para que se evite o conjunto de fenómenos de redução de racionalidade e criatividade de que os grupos frequentemente padecem. A motivação, satisfação, produtividade, criatividade e racionalidade são, de acordo com esta abordagem, fenómenos individuais, restringidos ou amplificados pelo grupo (Bastien e Hostager, 1988).

\section{Tese (B2): Nas organizações do futuro, a ansiedade é um mecanismo impor- tante de motivação.}

As organizações podem aproveitar a crescente turbulência nas suas envolventes para motivar os seus membros. Isto consegue-se importando essa instabilidade para dentro da organização, gerando um estado de ansiedade e ambiguidade nos seus elementos, que pode servir de motor para a motivação e levar a soluções mais criativas (Bastien e Hostager, 1988; Eisenberg, 1990). Alguns autores, entre os 
quais se destaca Peters (1987), afirmam que isto já escapou à vontade da organização, e passa agora a ser um dado. À empresa compete por isso apenas fornecer quadros de referência que levem os seus membros a valorar positivamente a ambiguidade e prosperar na ansiedade.

\section{Antítese (B2): Nas organizações de sucesso, a segurança é um mecanismo importante de motivação.}

As organizações devem absorver a crescente turbulência da envolvente, de modo que os seus colaboradores trabalhem num ambiente protegido da ansiedade que uma maior permeabilidade organizacional acarretaria (Kets de Vries e Miller, 1984). De facto, até mesmo autores que normalmente se enquadram na corrente dita moderna, afirmam que um estado de pressão e ansiedade elevadas podem reduzir a flexibilidade e a capacidade de adaptação dos membros da organização, quer considerados individualmente, quer enquanto grupo (Weick, 19--). Este escudo organizacional deve ser, segundo esta abordagem, o mais amplo possível Peters (!) (1987, p. 344) chega até apresentar como uma das quarenta e cinco receitas para que as organizações prosperem no caos, a necessidade de dar à força de trabalho uma "garantia de emprego permanente". O mesmo autor afirma que "dizer que só alguma garantia de segurança permitirá que as empresas induzam os seus empregados a (1) assumir cada vez mais riscos e (2) serem suficientemente flexíveis para lidar com a mudança constante, é quase uma verdade psicológica" (Peters, 1987, p. 348).

De facto, um dos papéis mais importantes do gestor é o de proteger a organização de variações na envolvente, "actuando como uma válvula entre a unidade que gere e aquilo que a rodeia" (Mintzberg, 1994, p. 19), reenquadrando a turbulência de forma a aparentar estabilidade. Surpreendentemente, esta necessidade de criar um ambiente hermético à turbulência exterior tem vindo a transportar a corrente dita tradicional para formas organizacionais pouco canónicas, como é o caso da organização em trevo (Handy, 1990), em que um pequeno núcleo de pessoas, em número insuficiente para as tarefas de que estão encarregadas (é este o segredo de Peters (1987) para o emprego permanente) tem de facto garantia de emprego, enquanto as restantes tarefas são subcontratadas e/ou entregues a membros da organização em part-time, de modo a acomodar flutuações na qualidade e quantidade da procura, sem sacrificar os membros do núcleo.

\section{Síntese (B2): Nas organizações a ansiedade num ambiente de segurança míni- ma é um mecanismo importante de motivação.}

As organizações têm um elevado grau de porosidade à envolvente. Não é possível manter um estado de segurança e estabilidade na organização, quando tudo o 
que a rodeia está em mutação acelerada. Isso não é sequer desejável. A presença de um contexto instável, que exige alguma velocidade de resposta por parte dos membros da organização potencia a flexibilidade, a capacidade de adaptação e, em última análise, o desempenho destes enquanto indivíduos e grupos (Brown e Eisenhardt, 1997). É importante, no entanto, que esteja presente na organização um nível mínimo de segurança que seja apenas o necessário para não paralisar a acção perante a mudança, de modo a explorar o potencial motivador da ansiedade. Esta segurança mínima é composta, essencialmente, por dois elementos complementares: uma cultura de experimentação/erro e uma rede de segurança que permita a tomada de riscos (Weick, 1999). Uma cultura de experimentação/erro implica que o sistema de valores da organização inclua atitudes favoráveis para aqueles que experimentam e, quando essa experimentação conduza a erros, para aqueles que transformam esses erros em aprendizagem útil à organização. Uma rede de segurança que permita a tomada de riscos implica que os membros da empresa sintam que assumir riscos e cometer erros (que advenham da inovação na aç̧ão e não do desleixo) não ameaça a sua permanência na organização, antes pelo contrário, algo que deve ser congruente com o sistema de remuneração (que deve recompensar/incentivar este tipo de comportamentos) (Picken e Dess, 1997). Note-se no entanto que isto está muito longe da garantia de emprego defendida pela corrente tradicional.

\section{Tese (B3): Nas organizações do futuro, a criatividade é privilegiada.}

O tipo de concorrência na maioria dos sectores de actividade gera e é gerada por mudanças descontínuas e que se sucedem a uma cadência elevada (Bettis e Hitt, 1995). Isto tem como consequências, entre outras: (1) uma rápida desactualização dos modelos mentais detidos pelos membros das organizações que os constituem e (2) o aparecimento de oportunidades e problemas - desafios - que não encontram ressonância no passado dessas empresas (Senge, 1990; Peters, 1992).

Para responder a estes desafios, a corrente moderna defende, por um lado, (1) a necessidade de dar maior ênfase à aprendizagem de ciclo duplo ( $\approx$ eficicácia $)$ em detrimento da aprendizagem de ciclo único ( $\approx$ eficiência) (Senge, 1990); e, por outro, (2) a necessidade de gerar variedade de pensamentos e comportamentos, de forma a compensar maior complexidade externa com maior complexidade interna. Isto implica que, de acordo com esta abordagem, aos gestores compete criar as condições para a maximização da criatividade na organização (Amabile, 1998), procurando libertar os seus membros de todas as barreiras que inibam o desenvolvimento e aplicação desta competência (Weick, 1999).

A resposta desta corrente de pensamento às elevadas taxas de insucesso diagnosticadas na produção de inovações por parte da organização (Craig e Hart, 
1992; Cooper, 1994), é que os erros são um mal necessário causado por variações (actos criativos) mal sucedidas e compensados pelos resultados daquelas que são mais bem aceitas pelo mercado.

\section{Antítese (B3): Nas organizações de sucesso, a rotinização é privilegiada.}

Esta abordagem, apesar de não ignorar o acréscimo da concorrência, defende que o seu impacto ocorre essencialmente ao nível do preço e do posicionamento (Porter, 1998), o que significa que o desafio que se coloca à empresa não é o da diferenciação pela criação de algo de novo, mas sim por fazer melhor o que já faz, ou seja, ou fazer melhor o seu produto/serviço, reduzindo o seu custo, ou fazer um produto/serviço melhor (qualidade na percepção do cliente), mantendo um posicionamento sustentável e rentável. Contudo, e como resposta aos sucessivos ataques de que esta perspectiva tem sido vítima, Porter (1996) parece contrariar esta perspectiva ao distinguir estratégia de eficácia operacional. No entanto, mantém uma relação implícita entre ambas, em que a segunda é condição sine qua non da primeira e continua a defender que a estratégia é "a criação de uma posição única e valiosa através de um conjunto diferente de actividades" (Porter, 1996, p. 68). Apesar desta reformulação, essa posição única acaba por se reportar às duas categorias anteriores de diferenciação com base no custo ou na qualidade do produto, que sustentam a escolha de mercados/nichos a servir pela empresa. Em ambos os casos, estamos assim perante um aumento de eficiência, obtida através da rotinização - normalmente ao nível do processo - que pode ser quantitativa (redução do custo), ou qualitativa (aumento da qualidade do produto/serviço) (Deming, 1986).

A criatividade tem algum espaço neste tipo de abordagens - quando, por exemplo, a empresa altera radicalmente o seu posicionamento competitivo - mas é sempre muito infrequente e por isso mais característica da obtenção de um equilíbrio pontuado do que de uma mudança incremental (Eisenhardt e Tabrizi, 1995).

Os erros não têm aqui lugar, devido ao elevado grau de prescrição que as caracteriza em todo o processo de produção, implementado directa (via supervisão) ou indirectamente (via estandardização) (Juran, 1988).

\section{Síntese (B3): Nas organizações, a rotinização da criatividade é privilegiada.}

Das correntes anteriores, podemos retirar as pressões que a turbulência da envolvente (Emery e Trist, 1965) impõe às organizações no sentido de uma mudança próxima do contínuo; no entanto, há também que ter em conta que este padrão de comportamento necessita de uma determinada dotação de recursos se as novas oportunidades que vai descortinando forem exploradas por utilização, ou seja, se 
forem rotinizadas de forma a serem suficientemente rentáveis. Isto significa que à aprendizagem de ciclo duplo ( $\approx$ eficácia) - à descoberta de novas oportunidades deve sempre seguir-se a de ciclo único ( $\approx$ eficiência) - o aproveitamento/rentabilização dessas oportunidades (Moorman e Miner, 1998). Trata-se então de maximizar a criatividade rotinizada, ou seja, maximizar o número de oportunidades aproveitadas e não apenas o número de oportunidades geradas/descobertas (Barrett, 1998). Neste âmbito, os erros são vistos como oportunidades que devem ser aproveitadas (também, mas não só, para aprender) (Weick, 1999). Trata-se então de promover a mudança incremental de forma a gerar mudanças radicais. Usando uma metáfora empregada por Peters (1992), o gestor aqui assemelha-se a um jardineiro que deve não só olhar para o que semeou, como também para as plantas que vão aparecendo alheias à sua intenção, já que estas podem transformar a beleza do seu jardim, da elegância de uma capa de revista para a complexidade da vida real.

\section{Tese (B4): Nas organizações do futuro, o treino serve para libertar os traba- lhadores.}

A teoria dita moderna partilha do conjunto de crenças e valores que McGregor (1960) rotulou de teoria Y. Consequentemente, acredita também que as organizações apenas devem limitar a liberdade dos seus membros pelo período de tempo necessário a que estes adquiram as competências requeridas para canalizar adequadamente o seu desempenho. A partir do momento em que estas competências estão presentes, essa limitação deve ser levantada de forma que os membros da organização possam aplicar todo o seu talento ao seu sucesso (Deming, 1986). O treino é entendido essencialmente como um processo de aquisição de competências e de crenças e valores (cultura) que os liberta para desempenhar as suas tarefas de forma excelente (Peters e Waterman, 1982). Os empregados não cometem erros, porque sabem como não o fazer.

\section{Antítese (B4): Nas organizações de sucesso, o treino serve para restringir os trabalhadores.}

Este tipo de abordagens partilha, por oposição às anteriores, das crenças e valores em relação à natureza humana que McGregor (1960) rotulou de teoria X. Por esta razão, o treino/formação tem como principal função a de assegurar a alocação de esforço/trabalho por parte dos trabalhadores à prossecução dos objectivos organizacionais definidos pelo topo. Quando o treino é concluído, é necessária a aplicação continuada de mecanismos de controlo para assegurar a manutenção da cooperação dos trabalhadores (Mintzberg, 1995). O treino é entendido como um processo de reforço da coordenação, que visa a tornar previsível o comportamen- 
to dos indivíduos através da estandardização de (1) competências e de (2) crenças e valores. Os empregados não cometem erros porque não têm autonomia para o fazer.

\section{Síntese (B4): Nas organizações de sucesso, o treino serve para libertar os trabalhadores, restringindo-os.}

De acordo com esta corrente, a liberdade dos trabalhadores só necessita de ser limitada de forma visível enquanto não forem criados mecanismos de coordenação invisíveis, ou seja, enquanto os membros não possuírem visões compatíveis da realidade nem um objectivo comum. O objectivo do treino, que se faz mais durante o desempenho enquanto membro de uma comunidade de prática (Bastien e Hostager, 1988) do que em sala, é o de dotar os indivíduos com um objectivo socialmente partilhado e com um conjunto mínimo de regras de interacção social que assegure a coordenação entre os esforços individuais via compatibilização da acção, sem no entanto criar uma percepção de limitação da liberdade individual (Weick, 1993), garantindo assim que os indivíduos alocam o seu nível mais elevado de desempenho à prossecução desse objectivo (Eisenberg, 1990). Os indivíduos não cometem erros, já que qualquer variação inesperada é utilizada como fonte de aprendizagem e de mudança, ou seja porque os erros não existem.

\section{Tese (B5): Nas organizações do futuro, a coordenação é feita via acção.}

A turbulência ambiental a que são sujeitas e a idade de um conjunto importante de organizações (Greiner, 1972; Baker, 1994), em conjunto com a presença cada vez mais intensa de mecanismos de pressão para a difusão de inovações administrativas/organizacionais (Abrahamson, 1991), tem levado ao aumento de pressões para a adopção de novas formas organizacionais. Recentemente, essa pressão levou a que os esforços de inovação organizacional/administrativa atingissem um nível mais fundamental, ao abandonar os esquemas de coordenação com base no binómio hierarquia/poder, que tem vindo a dominar o design organizacional (Powell, 1990), adoptando-se novas abordagens que se baseiam nos dois outros mecanismos de coordenação conhecidos: o mercado e a rede.

No que se refere ao mercado, a coordenação é explicada pela necessidade que os membros têm dos recursos (financeiros) uns dos outros, para levarem a cabo os seus objectivos individuais (Hayek, 1988), levando à emergência (ou ao desenvolvimento deliberado, se a gestão de topo da organização for entendida como um centro de proveito, que vende capital) dos objectivos da organização através de uma mão invisível, em tudo semelhante ao mecanismo do mesmo nome descrito por Smith (1991). Numa organização em rede, os seus membros estão coordenados entre si devido à necessidade de obter cooperação dos outros 
para alcançar os seus objectivos individuais - é o imperativo tecnológico defendido por Barnard (1938). Os indivíduos vão assim construindo um stock de direitos de reciprocidade e de reputação, e precisam de cooperar com os restantes membros da rede (contribuir para o cumprimento dos objectivos destes) para aumentar esse stock (Baker, 1994). Os objectivos organizacionais emergem (ou são deliberadamente desenvolvidos, se impostos por pessoas ou entidades externas à organização) através de uma mão invisível cujo mecanismo de coordenação não é mais o preço, mas a confiança/reputação (Powell, 1990). Em ambos os casos, a consecução dos objectivos organizacionais que vão emergindo processa-se sem a necessidade da presença deliberada de mecanismos de controlo, visíveis ou invisíveis. De facto, a presença de qualquer tipo destes mecanismos é desnecessária e perigosa.

É desnecessária já que, como foi explicado acima, o preço (no mercado) e a confiança/ reciprocidade (na rede) asseguram a coordenação suficiente entre os seus membros. É perigosa porque esta abordagem, que aqui designamos por moderna, afirma que dentro das organizações deve existir/ser gerada a variedade necessária para que os processos de selecção operados pela envolvente tenham material genético suficiente para encontrar inovações que sejam legitimáveis pelo mercado.

Para que esta diversidade seja possível, os mecanismos de coordenação organizacional devem ser não-intrusivos, ou seja, a sua presença não se pode fazer sentir de forma alguma entre os membros da organização, e devem promover a diversidade. (Powell, 1990; Semler, 1995). A perspectiva dos mercados internos afirma que a promoção da diversidade só aparece se a coordenação entre as unidades intra-organizacionais for feita com base no preço, e se a essas unidades for dada a liberdade de escolher entre fornecedores e clientes no seu mercado interno e no mercado externo (Halal, Geranmayeh e Pourdehnad, 1993). A perspectiva das organizações em rede afirma que indivíduos que exerçam tarefas com uma elevada componente de conhecimento não estão dispostos a verem a sua actividade ser fonte de qualquer tipo de controlo, por mais invisível que seja (Drucker, 1994). A coordenação entre estes indivíduos é feita com base na reprocidade, confiança e expectativas mútuas (Fukuyama, 1995). Deste modo, qualquer tentativa de imposição de um sistema de controlo, por mais invisível que seja (Perrow, 1986), nestas formas organizacionais, limitaria a sua capacidade de gerar variedade, de responder reactiva ou proactivamente à envolvente e, em última análise, de sobreviver. Finalmente, para esta corrente alcançar o propósito da organização passa essencialmente pelas relações informais entre os seus membros (Pfeffer, 1992), em detrimento das relações formais entre estes, que devem ser eliminadas sempre que possível (Forrester, 1965). 


\section{Antítese (B5): Nas organizações de sucesso, a coordenação é feita via estrutura.}

A crescente turbulência sentida na maioria das envolventes implica que só alguém com uma visão de conjunto (de topo) é capaz de conceber objectivos adequados para o sucesso da organização a longo prazo. É também da competência desta entidade a implementação dos mecanismos que asseguram que o esforço de toda a organização se encontra dirigido para esses objectivos. A coordenação entre os membros de uma organização deve assentar, por isso, num de dois processos: (1) a ordem, que entendemos aqui como substituição de conhecimento (Follett, 1940) ou (2) a partilha do conhecimento (Mintzberg, 1995). Dizemos que a coordenação é feita via ordem/substituição do conhecimento quando é implementada durante o processo de prossecução dos objectivos organizacionais. Nesta categoria incluem-se a supervisão directa (substituição total do conhecimento) e a estandardização de outputs ou processos (substituição parcial do conhecimento). Dizemos que a coordenação é feita via partilha de conhecimento quando é assegurada no momento da entrada do indivíduo para a organização estandardização de competências - ou imediatamente a seguir - estandardização de cultura/ideologia. Independentemente do mix de mecanismos de controlo escolhido, o que importa aqui é limitar a variedade de comportamentos e objectivos individuais, de forma que os resultados que a gestão de topo prescreve para a empresa sejam alcançados com o máximo de precisão e eficiência. Para esta abordagem, o alcance destes objectivos passa essencialmente pelas relações formais entre os seus membros, em detrimento das relações informais entre estes, que são vistas como um mal necessário inerente à condição humana, que desejavelmente seria eliminado (Fayol, 1949).

\section{Síntese (B5): Nas organizações, a coordenação é feita via acção enquadrada numa estrutura formal mínima.}

A turbulência da envolvente leva a que a acção realizada da organização seja não só resultado das suas intenções, como também de uma forte componente emergente. Os objectivos organizacionais emergem assim à medida que os indivíduos atribuem significado (sensemaking) à sua acção conjunta e às suas intenções prévias (Weick, 1999). A coordenação entre os membros da organização assenta assim em três elementos: (1) uma estrutura mínima de regras/padrões de relacionamento formalizados; (2) de objectivos pessoais compatíveis; e (3) de uma percepção compatível em relação aos desafios da envolvente (Weick, 1993). Esta coordenação é sempre invisível, e tem como objectivo fornecer à organização a estandardização mínima que, ao não inibir a diversidade e a geração de variedade (por ser mínima), permite que estas sejam convenientemente aproveitadas, atra- 
vés da aprendizagem/criação de rotinas (por ser estandardização). O modelo de base é o da comunidade de prática (Barrett, 1998), onde existe, por um lado, um conjunto de regras partilhadas que dizem essencialmente respeito à interacção social e, por outro, um núcleo de saber repartido por todos os seus membros dados como adquiridos quando existe interacção entre eles.

Deste modo, os objectivos organizacionais são realizados na medida em que resultam da intersecção (parcela compatível) dos objectivos individuais e porque são maioritariamente articulados retrospectivamente. Para esta abordagem, então, o alcance destes objectivos passa essencialmente pela criação de estruturas formais mínimas que potenciem e facilitem as relações informais entre os seus membros.

\section{Tese (B6): Nas organizações do futuro, a liderança é democrática.}

Como foi explicado anteriormente, esta corrente defende que devem ser os trabalhadores a planear e executar as tarefas necessárias à eficácia da empresa. Isto implica que a liderança deste tipo de organizações, conforme tem vindo a ser notório ao longo do texto, deve possuir um conjunto de características essenciais ao seu sucesso. A base/motivação de quem lidera pessoas neste tipo de organizações é a aspiração de servir (Greenleaf, 1977). Isto significa que o líder percepciona o seu papel como o de permitir que os outros (seus seguidores) tenham um desempenho excepcional. A sua tarefa principal é, assim, assegurar-se de que todos os indivíduos têm as condições necessárias para a realização plena do seu potencial. Motivar (através do exemplo) e ajudar os outros a praticarem mestria pessoal (personal mastery) são, por isso, as tarefas mais importantes do líder (Senge, 1990). Deste processo, o líder vê essencialmente satisfeitas as suas necessidades de pertença (Maslow, 1970), através das relações de suporte que estabelece com os seus seguidores. Este tipo de líder é por isso essencialmente motivado pela necessidade de afiliação, de acordo com a tipologia de McClelland (1961).

\section{Antítese (B6): Nas organizações de sucesso, a liderança é autoritária.}

Pelo seu lado, esta abordagem afirma que compete ao líder planear as tarefas que os trabalhadores vão executar, de modo a garantir a eficiência da empresa. Isto implica que a liderança deste tipo de organizações, conforme também pode ser detectado ao longo do texto, tem um leque diferente de características essenciais para o seu sucesso. A base/motivação do líder, neste tipo de organizações, é a aspiração de ser servido/de exercer poder. Isto significa que o líder percepciona o seu papel como o de procurar obter e demonstrar um desempenho pessoal excepcional. A sua missão principal é, assim, assegurar-se de que todos os indivíduos cumprem as tarefas que prescreveu, de forma a concretizar os objectivos da organização. A implementação e controlo são, deste modo, as suas funções mais importantes (jun- 
tamente com o planeamento, se este estiver incluído nas suas responsabilidades). Deste processo, o líder vê essencialmente satisfeitas as suas necessidades de reconhecimento (Maslow, 1970), através das relações de poder que estabelece com os seus subordinados. Este tipo de líder é por isso essencialmente motivado pela necessidade de poder, de acordo com a tipologia de McClelland (1961).

\section{Síntese (B6): Nas organizações, a liderança é democraticamente autoritária.}

Esta corrente defende que quer os trabalhadores quer os gestores têm como tarefa o planeamento em tempo real, ou seja, a convergência dos planos com a sua execução. Desta forma, o líder, neste tipo de organizações, deve possuir um conjunto de características essenciais, diferentes das patentes nas duas correntes anteriores. A base/motivação da liderança neste tipo de organizações é a aspiração de servir o grupo (que neste caso inclui o líder) (Eisenberg, 1990). Isto significa que o líder percepciona o seu papel como o de permitir que o grupo a que pertence, no seu conjunto, tenha um desempenho excepcional. A sua tarefa principal é, assim, dupla. Por um lado, (1) quando é o principal actor do grupo, deve assegurar-se de que as suas intenções são entendidas por este, de forma que os restantes membros possam contribuir para a excelência do seu desempenho, e que este contribua para a do grupo. Por outro lado, (2) quando é outra pessoa que assume esse papel, o ex-líder passa a ser responsável para contribuir para o desempenho desta, contribuindo de novo indirectamente para o do grupo. Deste processo, o líder/seguidor vê essencialmente satisfeitas as suas necessidades de realização (Maslow, 1970), através das relações de suporte que estabelece com os seus seguidores. Este tipo de líder é por isso essencialmente motivado pela necessidade de realização, de acordo com a tipologia de McClelland (1961).

\section{CONCLUSĀo}

As perguntas como? (organização) e o quê?/porquê? (estratégia) têm vindo a ser, senão dos mais prementes, pelo menos dos mais estudados desafios que o gestor enfrenta, não só nos nanosegundos dos anos 90 (Peters, 1992), como desde que a gestão emergiu como disciplina (Chandler, 1962; Galbraith, 1967). Desde essa altura que duas correntes antagónicas têm concorrido para responder a estas questões, provocando um aceso debate entre quem as estuda, e um sério dilema a quem tem de lhes responder na vida prática. O pouco que, comparativamente, há escrito sobre em que consiste, de facto, o trabalho do gestor, não nos permite escolher o vencedor deste combate. Não podemos também dizer que estamos perante um empate. Quem exerce a gestão, e quem a estuda no terreno, sabe 
que a realidade interna e externa das organizações não é, nem nunca foi, para utilizar a linguagem de Fonseca (1998), um relógio newtoniano. No entanto, as paisagem fractais são também uma metáfora que foge à compreensão daquilo que é a média de quem habita as organizações, além de estar ainda pouco legitimada e por isso ser ainda imprópria para consumo de accionistas e banqueiros. De facto, regras e estruturas são um lugar comum, mesmo nas organizações cujos resultados nos fazem exclamar UAU! (Peters, 1994), mas o que também é lugar comum nessas organizações são pessoas que dentro (e não apesar) dessa formalização conseguem, em conjunto, feitos extraordinários - feitos tão extraordinários como as melodias que um grupo de jazz improvisa em conjunto dentro (e não apesar) de uma estrutura constituída por fortes regras sociais e pela cristalização a que a pauta musical sujeita as canções. Associando o exercício de dialéctica que fizemos ao longo de todo este texto à imagem da improvisação em jazz, podemos dizer que esta não descreve a totalidade dos eventos que ocorrem durante um concerto. Há alturas em que mesmos os melhores músicos fingem improvisar, copiando solos que ouviram - ou tocaram - noutras ocasiões (Berliner, 1994). Do mesmo modo, o nosso modelo de síntese entre a tese moderna e a antítese tradicional também não descreve tudo o que faz um gestor, mas tal qual a improvisação em jazz, não pode ser considerado apenas um modelo normativo. Isto é fácil de entender se nos permitirmos um último exercício de dialéctica: o modelo que apresentamos é uma descrição normativa. É um modelo que está suficientemente próximo das preocupações quotidianas de quem exerce gestão para as descrever, mas ao mesmo tempo o suficientemente distante para as orientar.

\section{Nota}

${ }^{1}$ A atribuição do rótulo tese à corrente que privilegia eficácia e antítese à que privilegia a eficiência justifica-se por facilitar a apresentação da argumentação.

\section{ReferénCias Bibliográficas}

ABRAHAMSON, E.

Managerial fads and fashions : the diffusion and rejection of innovations. Academy of Management Review, v. 16, n. 3, p. 586-612, 1991.
AMABILE, T.

How to kill creativity. Harvard Business Review, v. 76, n. 4, p. 77-87, 1998. 
ANDREWS, K. R.

The concept of corporate strategy. In: MINTZBERG, H.; QUINN, J. B.; GHOSHAL, S. (Eds.). The strategy process : European edition. Englewwod Cliffs, NJ : Prentice-Hall, 1995. p. 55-64.

ARGYRIS, C.

Strategy, change and defensive routines. London : Pitman, 1985.

BAKER, W. E.

Networking smart : how to build relationships for personal and organizational success. New York: McGraw-Hill, 1994.

BARNARD, C.

The functions of the executive. Boston, MA : Harvard University Printing Office, 1938.

\section{BARRETT, F.}

Creativity and improvisation in jazz and organizations: implications for organizational learning. Organization Science, v. 9, n. 5, p. 605-622, 1998.

BASS, B.;

STOGDILL, R.

Bass and Stogdill's handbook of leadership. New York : Free Press, 1990.

BASTIEN, D. T.;

HOSTAGER, T. J.

Jazz as a process of organizational innovation. Communication

Research, v. 15, n. 5, p. 582-602, 1988.

BERLINER, $\mathrm{P}$.

Thinking in jazz. Chicago : University of Chicago Press, 1994.

BETTIS, R. A.;

HITT, M. A.

The new competitive landscape.

Strategic Management Journal, v. 16, p. 07-19, 1995.

BOHM, D.

On dialogue. London : Routledge, 1996.

BRANSON, R.

Loosing my virginity : how I've survived, had fun, and made a fortune doing business my way. New York : Time Books, 1998.

BROWN, S. L.;

EISENHARDT, K. M.

The art of continuous change : linking complexity theory and time-paced evolution in relentlessly shifting organizations. Administrative Science Quarterly, v. 42, p. 01-34, 1997.

BYHAM, W.;

COX, J.

Zapp! The lightning of empowerment. New York : Fawcett, 1998. 
CHANDLER, A.

Strategy and structure: chapters in the history of the industrial enterprise. Cambridge, MA : MIT Press, 1962.

COLLINS, J.;

PORRAS, J.

Built to last : successful habits of visionary companies. New York : Harper Business, 1997.

COOPER, R.

Third generation new product processes. Journal of Product Innovation Management, v. 11, p. 03-14, 1994.

CRAIG, A.;

HART, S.

Where now in new product development research. European Journal of Marketing, v. 26, n. 11, p. 01-49, 1992.

CROSSAN, M.;

SORRENTI, M.

Making sense of improvisation. Advances in Strategic Management, v. 14, p. 155-180, 1997.

D'AVENI, R.

Coping with hipercompetition : utilizing the new 7S framework. Academy of Management Executive, v. 9, n. 3, p. 45-57, 1995.
DEBONO, E.

Six thinking hats. New York : Little Brown \& Co, 1986.

DEVRIES, K.;

MILLER, D.

The neurotic organization.

London : Jossey-Bass, 1984.

DRUCKER, P. F.

Inovation and entrepreneurship. upd. ed. New York : Harper Business, 1993.

Post-capitalist society. New York : Harper Business, 1994.

EISENBERG, E. M.

Jamming : transcendence through organizing. Communication Research, v. 17, n. 2, p. 139-164, 1990.

EISENHARDT, K. M.;

TRABRIZI, B. N.

Accelerating adaptive processes : product innovation in the global computer industry. Administrative Science Quarterly, v. 40, p. 84-110, 1995.

EMERY, F.;

TRIST, E.

The causal texture of organizational environments. Human Relations, v. 26, n. 2, p. 21-32, 1965. 
FAYOL, H.

General and industrial management. London : Pitman, 1949.

FOLLETT, M. P.

The giving of orders. In: METCALF, H. C.; URWICK, L. (Eds.). Dynamic administration: the collected papers of Mary Parker Follet. New York : Harper \& Brothers, 1940. p. 50-70.

FONSECA, J.

Innovation : a property of complex adaptive systems.England, 1998. Thesis (Doctoral) - University of Hertfordshire.

FORRESTER, J.

A new corporate design. Industrial Management Review, v. 7, n. 1, p. 05-17, 1965.

FRITZ, R.

The path of least resistance : learning to become the creative force in your life. 2.ed. New York: Fawcett Columbine, 1989.

FUKUYAMA, F.

Trust : social virtues and the creation of prosperity. New York: Free Press, 1995.

GALBRAITH, J. K.

The new industrial state. Boston, MA : Houghton-Mifflin, 1967.
GREINER, L.

Evolution and revolution as organizations as organizations grow. Harvard Business Review, v. 50, n. 4, p. 83-92, 1972.

GARDNER, W.;

ROGOFF, B.

Children's deliberateness of planning according to task circumstances. Developmental Psychology, v. 26, n. 3, p. 480487, 1990.

GREENLEAF, R.

Servant leadership. New York :

Paulisi Press, 1977.

HACKMAN, J. R.;

OLDHAM, G. R.

Motivation through the design of work : test of a theory. Organizational Behavior and Human Performance, v. 16, p. 250-279, 1976.

HALAL, W.;

GERANMAYEH, A.;

POURDEHNAD, J.

Internal markets : bringing the power of free enterprise inside your organization. New York : John Wiley \& Sons, 1993.

HAMEL, G.;

PRAHALAD, C. K.

Competing for the future. Boston, MA: Harvard Business School Press, 1994. 
HANDY, C.

Understanding organizations. London : Penguin Books, 1976.

The age of unreason. Boston, MA : Harvard Business School Press, 1990.

HARRISON, M. E.

Diagnosing organizations: methods, models and processes. London: Sage Publications, 1987.

HARVEY, J.

The Abilene paradox and other meditations on management. London : Jossey-Bass, 1996.

HAYEK, F.

The fatal conceit : the errors of socialism. Chicago : Chicago University Press, 1988.

IMAI, M.

Kaizen. New York : McGrawHill, 1989.

JANIS, I.

Groupthink. Psychology Today, p. 271-279, Nov. 1971.

JURAN, J.

Juran's quality control handbook. New York : McGrawHill, 1988.

KATZENBACH, J.;

SMITH, D.

The wisdom of teams : creating the high performance organization. New York : Harper Business, 1994.

KAUFFMAN, S. A.

Escaping the red queen effect. The McKinsey Quarterly, v. 1, p. 119-129, 1995.

KOTLER, P.

Marketing management : strategy, process and implementation. Englewood Cliffs, NJ : Prentice-Hall, 1992.

LAWRENCE, P. R.;

LORSCH, J. W.

Organization and environment. Boston, MA : Harvard University Press, 1967.

LEVY, S.

Insanely great : the life and times of the Macintosh, the computer that changed everything. London: Penguin Books, 1995.

MASLOW, A.

Motivation and personality. New York : Harper \& Row, 1970.

MCCLELLAND, D.

The achieving society. New York : Van Nostrand, 1961.

MCGREGOR, D.

The human side of enterprise. New York : McGraw-Hill, 1960. 
MICKLETHWAIT, J.;

WOOLDRIDGE, A.

The witch doctors: what the management gurus are saying, why it matters and how to make sense of it. London : Heinemann, 1996.

MINTZBERG, $\mathrm{H}$.

The manager's job : folklore and fact. Harvard Business Review, p. 49-61, July/Aug. 1975.

Rounding out the manager's job. Sloan Management Review, p. 11-26, Fall 1994.

Five P's for strategy. In: MINTZBERG, H.; QUINN, J. B.; GHOSHAL, S. (Eds.). The strategy process : European edition. Englewwod Cliffs, NJ : Prentice-Hall, 1995. p. 13-21.

MOORMAN, C.;

MINER, A. S.

The convergence of planning and execution : improvisation in new product development. Journal of Marketing, v. 62, p. 01-20, 1998.

NONAKA, I.

The knowledge creating company. Harvard Business Review, v. 71, n. 3, p. 96-104, 1991.

PERROW, C.

The short and glorious history of organization theory. Organization Dynamics, p. 45-49, Summer 1973.
Complex organizations. 3. ed. New York: Random House, 1986.

PETERS, T. J.

Thriving on chaos. New York : Alfred A. Knopf, 1987.

Liberation management : the necessary disorganization for the nanosecond nineties. New York : Alfred A. Knopf, 1992.

The pursuit of wow! New York : Vintage, 1994.

Creating and maintaining excellence. In: KAWASAKI, G.; BOLLES, R. (Eds.). Hindsights: the wisdom and breakthroughs of remarkable people. New York : Warner Books, 1995. p. 40-50.

PETERS, T. J.;

WATERMAN, R. H.

In search of excellence. New York : Harper \& Row, 1982.

PETTIGREW, A.;

WHIPP, R.

Understanding the environment. In: MABEY, C.; MAYONWHITE, B. (Eds.). Managing change. London : Paul Chapman, 1993. p. 05-19.

PFEFFER, J.

Understanding power in organizations. California Management Review, p. 29-50, Winter 1992. 
PICKEN, J. C.;

DESS, G.

Out of (strategic) control. Organizational Dynamics, p. 3548, Summer 1997.

POOLE, M.;

VAN DE VEN, A.

Using paradox to build management and organization theories. Academy of Management Review, v. 14, p. 562-578, 1989.

PORTER, M. E.

What is strategy? Harvard Business Review, p. 61-78, Nov./ Dec. 1996.

Competitive advantage. New York : Free Press, 1998.

POWELL, W.

Neither market nor hierarchy : network forms of organization. In: CUMMINGS, L. L.; STAW, B. M. (Eds.). Research in organizational behavior. Greenwich : Jay Press, 1990. p. 295-336.

ROBBINS, S.

Organization theory : structure, design and applications. Englewood-Cliffs, NJ : PrenticeHall, 1990.

ROMANELLI, E.; TUSHMAN, M.

Organizational transformation as punctuated equilibrium : an empirical test. Academy of Management Journal, v. 5, p. 1141-1166, 1994.

SAYLES, L.

The managerial world : expectations vs. reality. In: SAYLES, L. (Ed.). Leadership. New York : McGraw-Hill, 1989. p. 01-24.

SEMLER, R.

Maverick. New York : Warner Books, 1995.

SENGE, P. M.

The fifth discipline : the art and practice of the learning organization. London : Century Business, 1990.

SMITH, A.

Wealth of nations. New York : Prometheus Books, 1991.

STACEY, R. D.

Complexity and creativity in organizations. San Francisco : Berrett-Koehler, 1996.

STALK, G.

Time : the next source for competitive advantage. Harvard Business Review, v. 66, n. 4, p. 31-41, 1988.

TAYLOR, F.

Scientific management. New York : Harper \& Row, 1947. 
VAN DE VEN, A.;

POOLE, M.

Explaining development and change in organizations. Academy of Management Review, p. 510-540, 1995.

WEICK, K. E.

The social psychology of organizing. 2. ed. New York : McGraw-Hill, 1979.

Organizational redesign as improvisation. In: HUBER, G. P.; GLICK, W. H. (Eds.). Organizational change and redesign : ideas and insights for improving performance. Oxford : Oxford University Press, 1993. p. 346-379.

The aesthetic of imperfection in orchestras and organizations. In: CUNHA, M. P.; MARQUES, C. A. (Eds.). Readings in organization science. Lisboa : ISPA, 1999.

\section{Tools and tragedies in wildland} firefighting : barriers to risk mitigation. Unpublished manuscript, University of Michigan, 19--. 